\title{
ДИСКУССИИ
}

\section{Инновационная модернизация социально-экономической системы региона: совершенствование кластерной политики в условиях глобализации}

\author{
Белякова Г.Я.' ${ }^{12}$ Батукова Л.P. ${ }^{13}$
}

Задача инновационной модернизации сочиально-экономической системы региона в условиях глобализащии развития может быть решена только при эффективной кластеризации экономического пространства, что обеспечивается реальным участием всех заинтересованных институтов общества в модернизачии.

Технологические платформы выступают инструментом вовлечения общественных институтов в процесс инновационной модернизации в условиях глобализации $u$ инновачионного развития. Система управления инновационной модернизацией региональной системы долюна формироваться с учетом методологии технологических платформ.

$J E L: A 10$

Ключевые слова: модернизация, инновачионная модернизация, инновачионное развитие, кластерная политика, технологические платформы, функиии технологических платформ

\section{Проблема формирования эффективной кластерной политики в регионах}

Для осуществления инновационной модернизации в условиях глобализации наиболее приемлемой альтернативой отраслевому принципу развития промышленного производства выступает кластерный подход. Но кластерное развитие территорий далеко не всегда оправдывает ожидания ученых и политиков. Это обусловлено во многом тем, что в условиях глобализации кластерное развитие требует особых подходов.

Наиболее общее определение сущности кластерного образования, а соответственно и подхода к его организации, дал М. Портер: «Кластер, или промышленная группа, - это группа соседствующих взаимосвязанных компаний и связанных с ними организаций, действующих в определенной сфере и характеризующихся общностью деятельности и взаимодополняющих друг друга».

Основной целью формирования кластера в данном, классическом понимании является достижение синергетических эффектов на основе комбинации функциональных взаимодействий, нахождения новых организационных решений на базе взаимосвязи, взаимодействия и взаимодополнения структур из различных областей бизнеса и прочих организационных систем.

Но в условиях функционирования глобального механизма инновационного развития на первое место по воздействию на развитие экономических систем выходит освоение принципиально новых (в том числе лабораторных) технологий, действие которых основано на новых физических принципах и эффектах, а также новых систем деятельности и практики.

\footnotetext{
12 Доктор экономических наук, профессор кафедры международного бизнеса, Сибирский федеральный университет, Институт управления бизнес-процессами и экономики, Красноярск.

13 Кандидат экономических наук, доцент кафедры экономики и менеджмента, Сибирский федеральный университет, Институт управления бизнес-процессами и экономики, Красноярск.
} 
Поэтому кластер начинает выступать не только оптимизирующим механизмом. Он становится механизмом запуска и раскрутки новых технико- и социально-экономических систем деятельности, механизмом технического перевооружения предшествующего технопромышленного уклада.

С учетом глобального инновационного развития центральным моментом (идеей, предпосылкой) формирования кластера является теперь не столько территориальногеографическое сближение, объединение, сколько организация:

1) полномасштабной производительной системы, объединяющей фундаментальную практикоориентированную науку;

2) мультиотраслевой и полисферной экономической практики на основе «технодинамики и технологической диффузии новых решений не по границам отраслей и переделов, а в соответствии с принципом инновационной восприимчивости» различных областей деятельности;

3) прорывного организационного ядра и конкурентной рыночной среды, воспринимающей и реализующей технологии и продукты нового технопромышленного уклада.

Кроме того, целью создания кластера часто является:

1) создание многофункционального продукта на основе передовой технологии, который в том или ином виде может внедряться в различных областях социальноэкономической практики, коренным образом преобразуя всю систему;

2) создание двойного маркетингового кольца, суть которого в формировании перехода от маркетинга продукта к маркетингу нового стиля жизни, и от маркетинга человека, употребляющего данный продукт и услугу к маркетингу вещи;

3) инвестиционное проектирование и построение финансово-инжиниринговой компании, обеспечивающей реализацию мегапроектов на основе альтернативного набора перспективных проектных продуктов и учета рисков, а не дисконтирования финансового потока.

Все это обеспечивает создание высокотехнологичных рабочих мест в рамках кластерных проектов, а соответственно - инновационное развитие российских регионов. Именно поэтому кластерное развитие сегодня становится важнейшим направлением региональной политики.

В 2008 году Минэкономразвития России была принята Концепция кластерной политики в стране, в рамках которой были выделены три основные направления стимулирования процесса формирования кластеров:

1. Содействие институциональному развитию кластеров, в первую очередь разработка стратегии их развития:

- стимулирование инноваций и коммерциализации технологий;

- содействие в предоставлении консультационных услуг;

- мониторинг и прогнозирование потребностей рынка труда, планирование, участие в разработке государственного задания на подготовку специалистов;

- разработка и распространение руководств и пособий по организации управления на предприятиях с учетом отраслевой специфики.

2. Меры, направленные на повышение конкурентоспособности участников кластера:

- содействие разработке программ долгосрочных партнерских исследований, кооперации предприятий при финансировании и реализации НИОКР;

- субсидирование части затрат предприятий на создание промышленных образцов, регистрацию и правовую охрану за рубежом изобретений;

- установление льгот по уплате региональных и местных налогов и сборов, а также налога на часть прибыли, подлежащей уплате в бюджет субъекта РФ; создание особых экономических зон регионального уровня;

- совместная реализация образовательных программ (материально-техническое, технологическое и кадровое обеспечение целевой подготовки). 
3. Формирование благоприятных условий для развития кластера:

- инвестирование в развитие инженерной и транспортной инфраструктур, жилищное строительство с учетом задач развития кластеров, реализация мер налогового регулирования для участников кластеров;

- финансирование инноваций в рамках федеральной целевой программы «Исследования и разработки по приоритетным направлениям развития научнотехнологического комплекса России на 2007-2012 годы»: обеспечение научным оборудованием центров коллективного пользования, поддержка проектов выполнения НИР и НИОКР;

- программы Фонда содействия развитию малых форм предприятий в научнотехнической сфере (Фонд Бортника): поддержка создания новых инновационных предприятий;

- помощь в реализации инновационных проектов, выполняемых малыми инновационными предприятиями на основе собственных разработок и при участии вузов;

- поддержка НИОКР, в том числе проводимых предприятиями для освоения лицензий на новые технологии и технические решения, приобретаемых у российских вузов, академических и отраслевых институтов.

Таким образом, промышленная политика, ориентированная на формирование кластеров, стала ключевым механизмом реализации стратегии и программ социальноэкономического развития российских регионов. В ряде регионов были приняты отдельные программы развития кластеров или созданы организационные структуры по их развитию.

Однако повышенная активность в данной сфере не обеспечила повсеместного формирования по-настоящему современных, передовых кластерных образований, способных стать точками инновационного роста окружающих территорий и систем.

Подавляющая доля кластеров до настоящего времени формируется или случайно, или в развитие принятых еще во времена СССР решений о территориально-производственных комплексах. Это не обеспечивает необходимых темпов инновационных преобразований. Одним из наиболее ярких примеров является «Дорожная карта» пилотных проектов, предлагаемых для реализации в рамках первого этапа плана «Новая индустриализация» (см. табл. 1).

Таблица 1 «Дорожная карта» пилотных проектов, предлагаемых для реализации в рамках первого этапа плана «Новая индустриализация» (выдержка)

\begin{tabular}{|c|c|c|c|}
\hline Регионы & Название проекта & $\begin{array}{l}\text { Сектор по } \\
\text { стратегии }\end{array}$ & Краткое описание \\
\hline $\begin{array}{l}\text { Ростовская } \\
\text { область }\end{array}$ & $\begin{array}{l}\text { Кластер южного } \\
\text { сельхозмашиност } \\
\text { роения }\end{array}$ & $\begin{array}{l}\text { Импортоз } \\
\text { амещение }\end{array}$ & $\begin{array}{l}\text { Создание на базе «Россельмаша» кластера } \\
\text { предприятий, } \\
\text { сельхозтехнику, комплектующие к ней, а } \\
\text { также развитие отраслевого НИОКРа }\end{array}$ \\
\hline $\begin{array}{l}\text { Вологодская } \\
\text { область }\end{array}$ & $\begin{array}{l}\text { Кластер } \\
\text { производству } \\
\text { молока } \\
\text { молочных } \\
\text { продуктов }\end{array}$ & $\begin{array}{l}\text { Сельское } \\
\text { хозяйство }\end{array}$ & $\begin{array}{lrr}\text { Создание } & \text { кластера } & \text { обеспечит } \\
\text { восстановление } & \text { комплекса } \\
\text { агропредприятий } & \text { по } & \text { производству } \\
\text { отечественной молочной продукции за счет } \\
\text { совместного развития предприятиями } \\
\text { современных } & \text { технологий, } \\
\text { маркетинга и сбытовых структур }\end{array}$ \\
\hline $\begin{array}{l}\text { Ленинградская } \\
\text { область }\end{array}$ & $\begin{array}{l}\text { Кластер по } \\
\text { переработке } \\
\text { природного газа и } \\
\text { производства }\end{array}$ & $\begin{array}{l}\text { Глубокая } \\
\text { переработ } \\
\text { ка сырья }\end{array}$ & $\begin{array}{l}\text { Создание ряда ориентированных на } \\
\text { экспорт и основанных на новейших } \\
\text { технологиях производств по переработке } \\
\text { газа в месте выхода «Северного потока» с }\end{array}$ \\
\hline
\end{tabular}




\begin{tabular}{|c|c|c|c|}
\hline & $\begin{array}{l}\text { аммиака, } \\
\text { минеральных } \\
\text { удобрений, } \\
\text { капролактама и } \\
\text { продукции из них } \\
\end{array}$ & & территории России \\
\hline $\begin{array}{l}\text { Костромская } \\
\text { область }\end{array}$ & $\begin{array}{l}\text { Ювелирный } \\
\text { кластер } \\
\text { «Кострома } \\
\text { ювелирная } \\
\text { столица» }\end{array}$ & $\begin{array}{l}\text { Импортоз } \\
\text { амещение }\end{array}$ & $\begin{array}{lccc}\text { Создание } & \text { кластера } & \text { по } & \text { производству } \\
\text { ювелирных } & \text { изделий } & \text { посредством } \\
\text { кооперации и } & \text { поддержки } & \text { перспективных } \\
\text { предприятий } & & \end{array}$ \\
\hline $\begin{array}{l}\text { Томская } \\
\text { область }\end{array}$ & $\begin{array}{l}\text { Образовательный } \\
\text { кластер по } \\
\text { экспорту } \\
\text { образования } \\
\text { «ИНО Томск } \\
2020 » \\
\end{array}$ & Экспорт & $\begin{array}{l}\text { Создание мощного образовательно- } \\
\text { инновационного центра, привлекающего } \\
\text { иностранных студентов на уже имеющейся } \\
\text { университетской, исследовательской и } \\
\text { инновационной базе Томской области }\end{array}$ \\
\hline
\end{tabular}

Очевидно, что в «Дорожной карте» приведены ряд проектов, которые являются продолжением территориально-производственного развития еще советского периода. Методологически данный перечень проектов основан на двух принципах. Первый принцип кластеры должны более-менее равномерно распределяться (по-видимому, в соответствии с количеством населения) по территории РФ и «давать работу имеющемуся населению». Второй принцип - ресурсоориентированность, что означает формирование производственной системы, сложившейся на основе ресурсно-сырьевой базы. Основная рыночная цель предлагаемой кластерной политики - импортозамещение.

Достоинством предлагаемой инициативы является стремление авторов проекта сделать акцент на создание рабочих мест с повышенной производительностью. Но при этом авторы предлагают: «Формировать рабочие места (с производительностью по 3 млн руб. в год каждое) планируется преимущественно в отраслях, ориентированных на внутренний спрос, глубокой переработке российского сырья, энергетическом, атомном и других секторах машиностроения, сельском хозяйстве, постиндустриальных секторах экономики и частных компаниях в социальной сфере (медицине, образовании, социальных услугах)».

Несколько иначе к развитию кластеров в РФ подходят Е.Б. Ленчук и Г.А. Власкин. Они предлагают выделить экспортноориентированные отрасли промышленности, не охваченные процессами кластерообразования, и на их основе сформировать соответствующие кластеры (табл. 2).

Таблица 2

Ведущие экспортноориентированные отрасли промышленности, в рамках которых предлагается создать кластеры

\begin{tabular}{|l|l|l|}
\hline \multicolumn{1}{|c|}{$\begin{array}{c}\text { Отрасль (подотрасль) } \\
\text { промышленности }\end{array}$} & \multicolumn{1}{|c|}{$\begin{array}{c}\text { Объем экспорта продукции } \\
\text { кластеров обеспечивает, по } \\
\text { экспертной оценке, перспективы } \\
\text { занять долю мирового рынка, \% }\end{array}$} \\
\hline $\begin{array}{l}\text { Производство } \\
\text { минеральных удобрений }\end{array}$ & Агропромышленный & 16,88 \\
\hline $\begin{array}{l}\text { Производство } \\
\text { синтетического каучука }\end{array}$ & $\begin{array}{l}\text { Производство } \\
\text { пластических материалов }\end{array}$ & 9,10 \\
\hline $\begin{array}{l}\text { Производство материалов } \\
\text { на основе неорганических } \\
\text { соединений }\end{array}$ & $\begin{array}{l}\text { Производство химических } \\
\text { продуктов }\end{array}$ & 8,09 \\
\hline Производство слоистой & Производство отделочных & 6,56 \\
\hline
\end{tabular}




\begin{tabular}{|c|c|c|}
\hline древесины & $\begin{array}{l}\text { материалов и } \\
\text { строительного } \\
\text { оборудования }\end{array}$ & \\
\hline $\begin{array}{l}\text { Производство и } \\
\text { использование } \\
\text { электроэнергии }\end{array}$ & $\begin{array}{l}\text { Производство } \\
\text { энергетического } \\
\text { оборудования и энергии }\end{array}$ & 2,53 \\
\hline $\begin{array}{l}\text { Производство реактивных } \\
\text { двигателей }\end{array}$ & $\begin{array}{l}\text { Производство двигателей } \\
\text { для космических } \\
\text { аппаратов }\end{array}$ & 2,11 \\
\hline $\begin{array}{l}\text { Производство печатной } \\
\text { продукции }\end{array}$ & $\begin{array}{l}\text { Издательская и } \\
\text { полиграфическая } \\
\text { деятельность }\end{array}$ & 1,21 \\
\hline $\begin{array}{l}\text { Производство чертежных } \\
\text { и измерительных } \\
\text { приборов }\end{array}$ & $\begin{array}{l}\text { Производство } \\
\text { аналитических приборов }\end{array}$ & 0,74 \\
\hline $\begin{array}{l}\text { Производство кабелей и } \\
\text { проводников }\end{array}$ & $\begin{array}{l}\text { Производство средств } \\
\text { связи }\end{array}$ & 0,33 \\
\hline
\end{tabular}

Анализ данного подхода в кластерной политике позволяет сделать вывод о том, что в ее основе лежит принцип ресурсоориентированности. Отличие от прочих состоит в том, что при данном подходе не рассматриваются в качестве базовых для образования кластеров добывающие отрасли в чистом виде, переработка аграрной продукции и услуги, а также отрасли, ориентированные исключительно на внутренний рынок. Авторы сосредоточили свое внимание на промышленно-производственной сфере деятельности, обеспечивающей экспортные потоки в рамках сложившейся экономической модели.

Рассмотрим пример кластерного развития территории, который имеет место на практике. Проанализируем комплекс кластеров Красноярского края. Основными кластерами Красноярского края являются:

a) машиностроительный (транспортное машиностроение),

б ) агропромышленный,

в) машиностроительный (производственное машиностроение),

г) строительный,

д) лесной.

На рисунке 1 представлены схемы указанных кластеров.

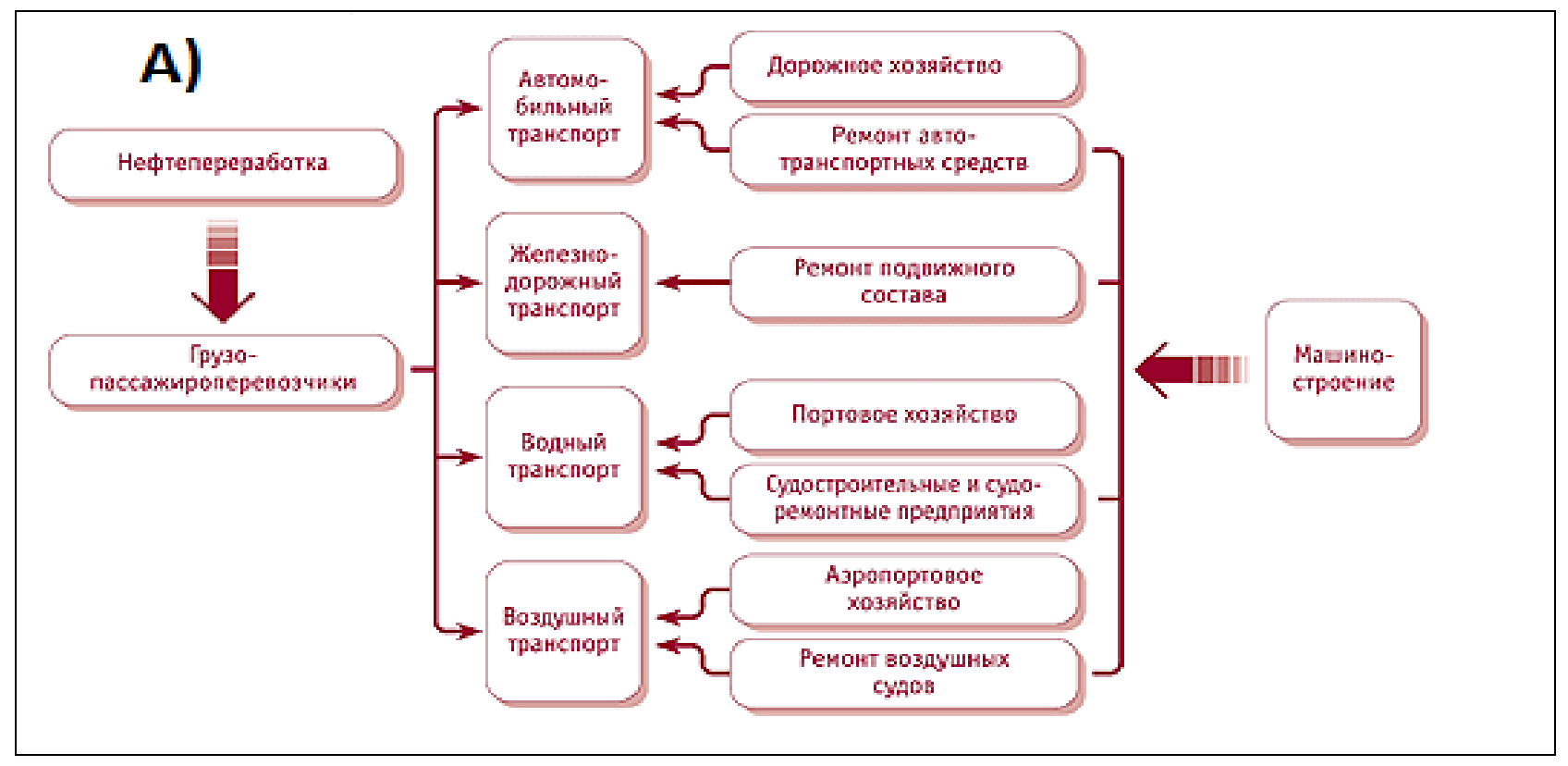




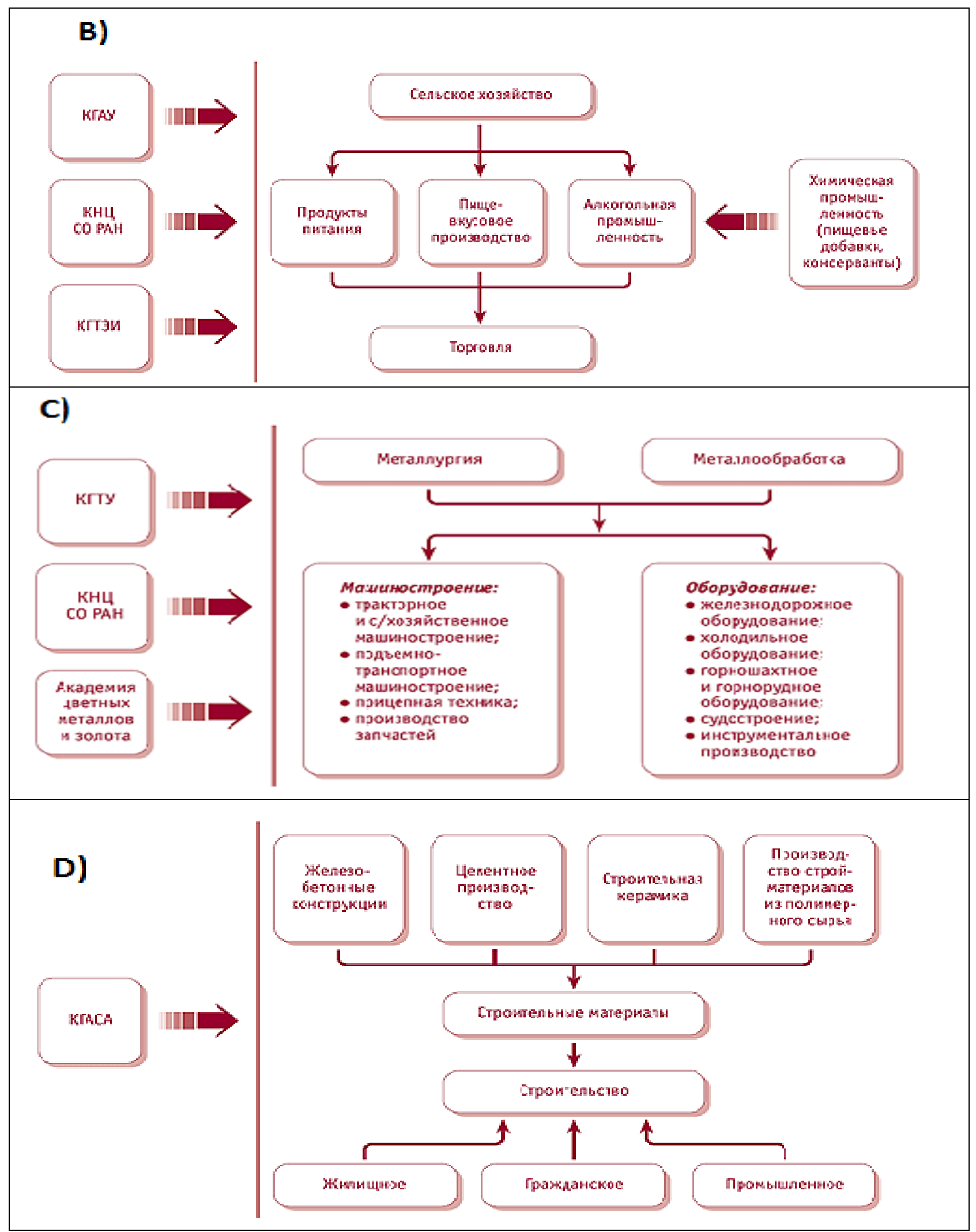

Рисунок 1. Примеры схем основных кластеров Красноярского края

Каждый кластер сформирован по своему принципу. В том числе:

а) транспортный кластер - по принципу общности продукции, рынка поставщиков ресурсов (сетевой принцип);

б) агропромышленный кластер - по сетевому принципу, причем здесь установлена значимая взаимосвязь с торговлей; 
в) машиностроительный (производственное машиностроение) - по принципу общности «оказываемых услуг и относительной самостоятельностью отдельных звеньев.

г) строительный кластер - по принципу общности продукции и рынка сбыта продукции;

д) лесной - по принципу технологической цепочки.

Формирование приведенных кластеров опирается на те же методологические принципы: ориентация на имеющиеся ресурсы, стремление более эффективно использовать созданные во времена СССР мощности, развить проекты по добыче полезных ископаемых, заместить импортную продукцию более дешевыми аналогами, параллельно создавая рабочие места.

Положительным аспектом данной кластерной политики является попытка использовать геоэкономическое положение территории края для создания межконтинентальных транспортных коридоров при формировании транспортного кластера. Данная цель является наиболее прогрессивной частью региональной политики промышленного развития Красноярского края. Это открывает новые возможности инновационного развития, включения в международный механизм создания и распределения инновационных продуктов и услуг в качестве производителя последних.

Но следует отметить, что для реализации данной цели необходима соответствующая институциональная и организационная поддержка. Как минимум нужна целенаправленная комплексная программа развития данного проекта в рамках транспортного кластера, трансформация законодательства, должны быть созданы исследовательские институты и лаборатории, которые бы обеспечили проведение и продвижение фундаментальных и прикладных исследований в заданном направлении. Указанные цели не обозначаются в качестве основополагающих при формировании транспортного кластера.

Следует отметить, что все прочие кластеры сформированы аналогичным образом. Институциональная и организационная поддержка их не проработана в должной мере и из их структуры совершенно не ясно, каков механизм включения данных кластеров в контекст мирового инновационного развития.

Анализ приведенных подходов к организации кластеров свидетельствует о том, что методология кластерной политики требует совершенствования. Это даст возможность практикам опираться на соответствующие научные рекомендации.

\section{Технологические платформы как инструмент формирования и развития современных инновационно ориентированных кластеров в регионах}

Очевидно, что кластерная политика должна формироваться в тесной связке с международным механизмом инновационного развития. В настоящее время данная проблема может быть решена на уровне института технологических платформ.

Цель принимаемых в рамках технологических платформ решений - это развитие производительных сил посредством более эффективного геоэкономического перераспределения их в системе мирового хозяйства, аккумулирование необходимого объема финансово-инвестиционных ресурсов для масштабного технического и технологического перевооружения производственной базы, создание условий для успешного производства и внедрения принципиально новых научных и технологических принципов.

Поэтому в качестве основополагающих задач функционирования технологических платформ выделяют следующие. Во-первых, это необходимость убедить правительство, а также финансовые и прочие организации в необходимости поддерживать организационными, финансово-экономическими, политическими и прочими мерами передовые идеи, сформированные в области науки и техники. Новизна предлагаемых наукой и техникой идей является не только их достоинством, но и вызывает много проблем. Прежде чем проложить себе путь в экономику, найти своих сторонников, любая идея должна быть осознана обществом как полезная. Особенно важно, чтобы она была осознана на том 
социально-экономическом уровне, на котором принимаются решения в отношении поддержки или не поддержки соответствующих идей.

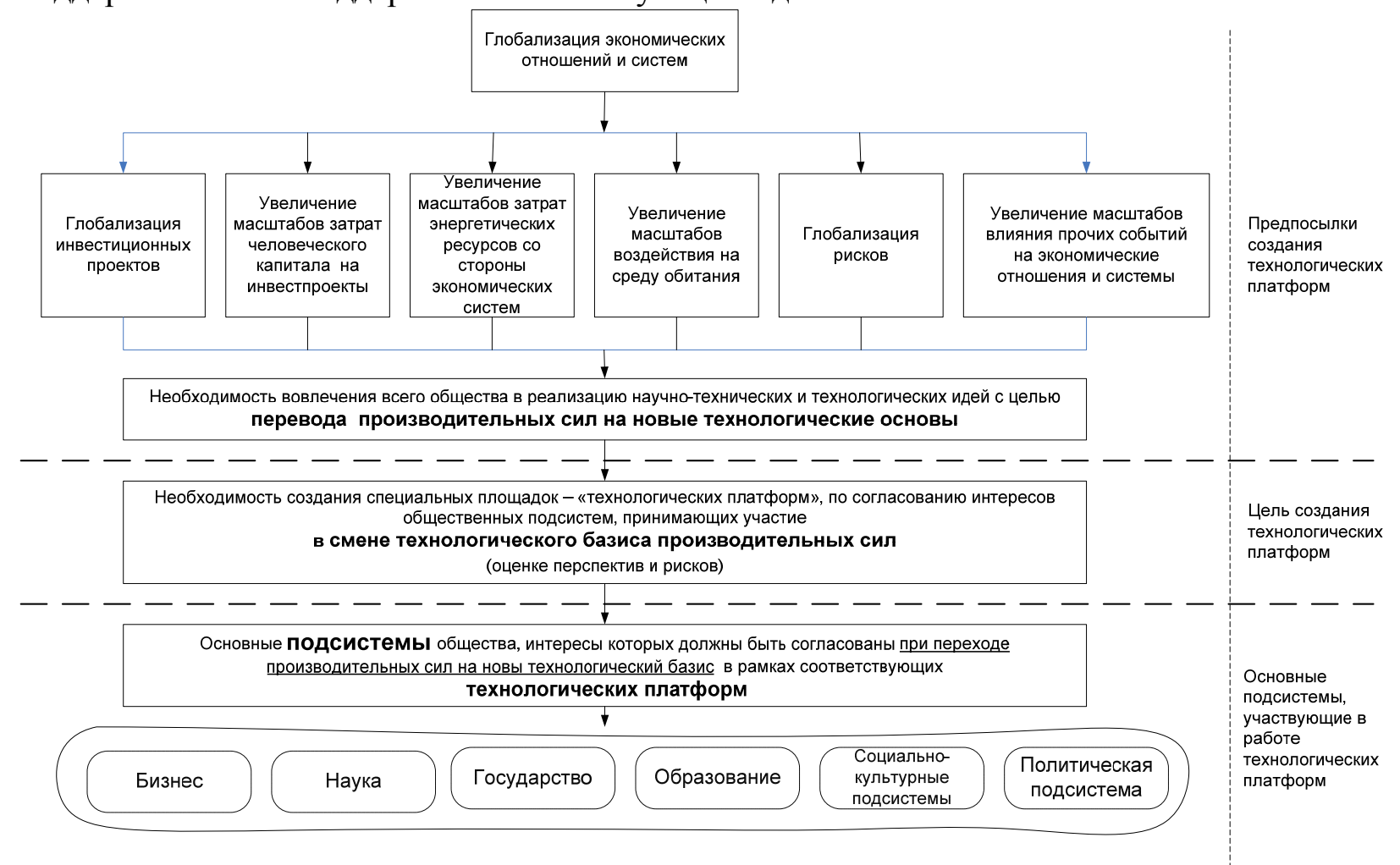

Рисунок 2. Предпосылки и цели создания технологических платформ

То есть в данном случае технологические платформы призваны выполнять функцию продвижения передовых научных идей на те социальные уровни, которые ответственны за формирование социально-экономической стратегии нации, за принятие управленческих решений макроуровня. Поддержка со стороны топ-элиты общества в данном случае принципиально важна, так как реализация современных высокотехнологичных идей чаще всего требует значительных ресурсов и консолидации усилий на уровне всего государства или нескольких государств и даже всего мирового сообщества. Для реализации современных проектов в области высокотехнологичной медицины и передовой энергетики, освоения космоса, биотехнологий и генной инженерии, нано-металлургии и в других областях требуется системная консолидация усилий многих специалистов, надежная ресурсная база и возможность осуществления долговременных исследований, а также значительные затраты на стадии коммерциализации. Указанные макропроекты не под силу отдельному, даже очень крупному бизнесу. Но объединенное вокруг определенных идей человеческое сообщество, включая производственный бизнес, финансовые институты, науку, образовательные и исследовательские центры, обеспеченное режимом наибольшего благоприятствования со стороны государства или ряда государств, способно решать и столь масштабные задачи.

Вторая задача, которая решается в рамках технологических платформ, - это необходимость произвести предварительную оценку выдвигаемых наукой идей с точки зрения их коммерческих перспектив, системных эффектов. Предлагаемая научным сообществом идея ученым может показаться весьма оригинальной. Но прежде чем вкладывать ресурсы в ее развитие, необходимо убедиться, что она будет востребована потребительским рынком, а также что она повлечет положительные, а не отрицательные системные эффекты. Часто случается так, что наука предлагает идеи, которые значительно опережают свое время и поэтому не могут найти своего потребителя; либо предприятиям требуются слишком большие инвестиции на доведение таких передовых идей до коммерческого уровня. Это приводит к значительному повышению инвестиционных рисков и снижению экономической эффективности. Если такую идею поддержать на 
докоммерческой стадии усилиями всего общества, то когда дело дойдет до коммерческой реализации, ее некому будет передать. Бизнес-сообществу не нужны идеи и технологии, которые не приносят достаточной прибыли. Также научно-техническим сообществом часто выдвигаются идеи, которые вследствие своей креативности могут значительно повысить эффективность системы труда общества, но при этом вызвать нежелательные социальные последствия.

Все это должно быть выяснено соответствующими специалистами еще на стадии первичного рассмотрения идеи. Таким образом, второй функцией (рисунок 3) технологической платформы выступает функция всесторонней, комплексной оценки и систематизации технических и технологических идей.

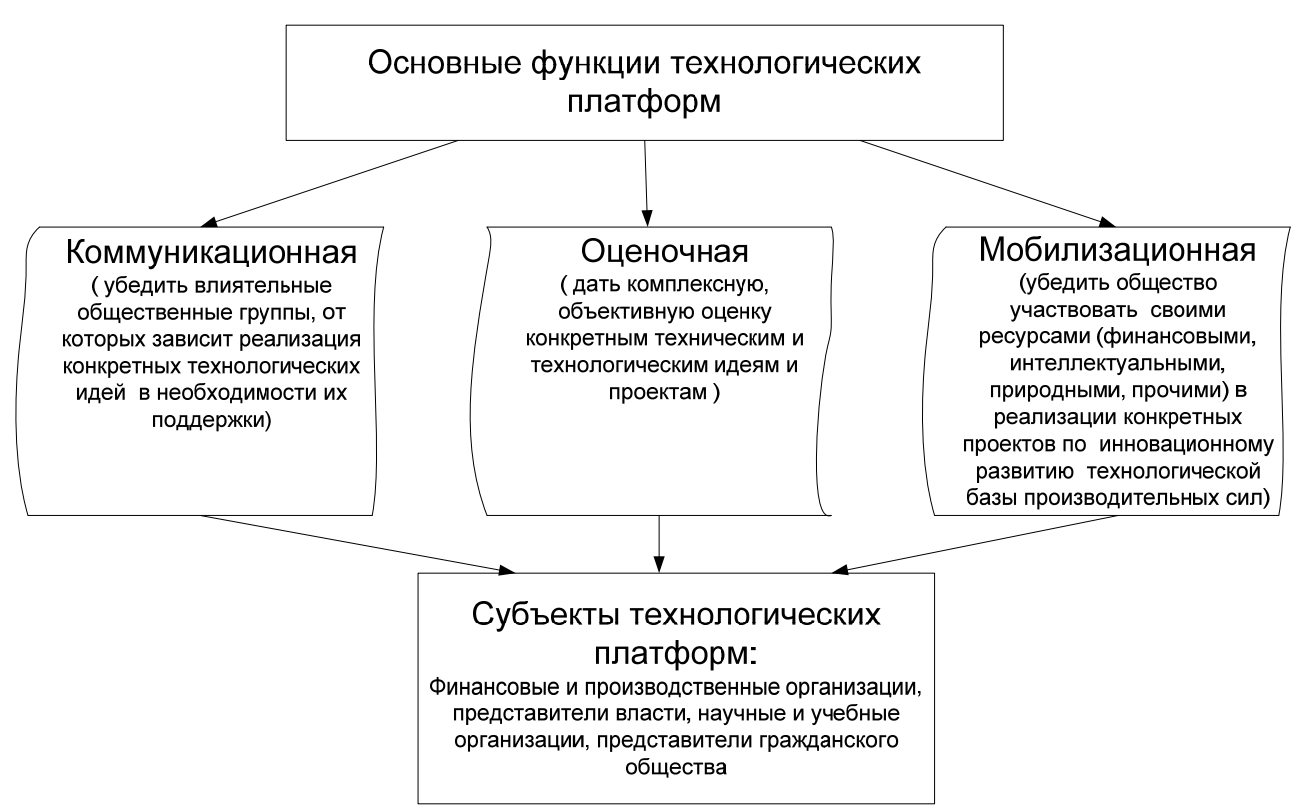

Рисунок 3. Основные функции технологических платформ

Третьей задачей является мобилизация общественных ресурсов на решение стратегических задач развития конкретной социально-экономической системы. Так как для продвижения передовых инновационных технологических проектов требуется значительное количество самых разнообразных ресурсов, то еще одной значимой функцией технологических платформ является функция мобилизационная. Если технологическая платформа способна осуществить указанные функции, то можно говорить о жизнеспособности и реальном функционировании соответствующей платформы.

Таким образом, очевидно, что технологические платформы являются институтом, в рамках которого складывается механизм формирования обществом крупных инвестиционных проектов, их оценки и продвижения. Данный механизм позволяет увязать на взаимовыгодной основе как интересы регионов, так и бизнес-сообщества и прочих институтов общества. Это делает институт технологических платформ незаменимым элементом системы управления развитием региона в условиях глобализации.

Сказанное о технологических платформах позволяет утверждать, что они должны выступить в качестве основного организационного аспекта и движущей силы развития кластерного подхода в условиях глобализации. В рамках технологических платформ могут формироваться, проходить критическую оценку и получать организационное и финансовое наполнение идеи создания новых эффективных инновационных кластеров. Недостаточное привлечение к формированию кластеров различных институтов общества и бизнеса является причиной сведения кластерной политики в ряде случаев исключительно к тиражированию идеи ТПК советского периода, а также к импортозамещению. 


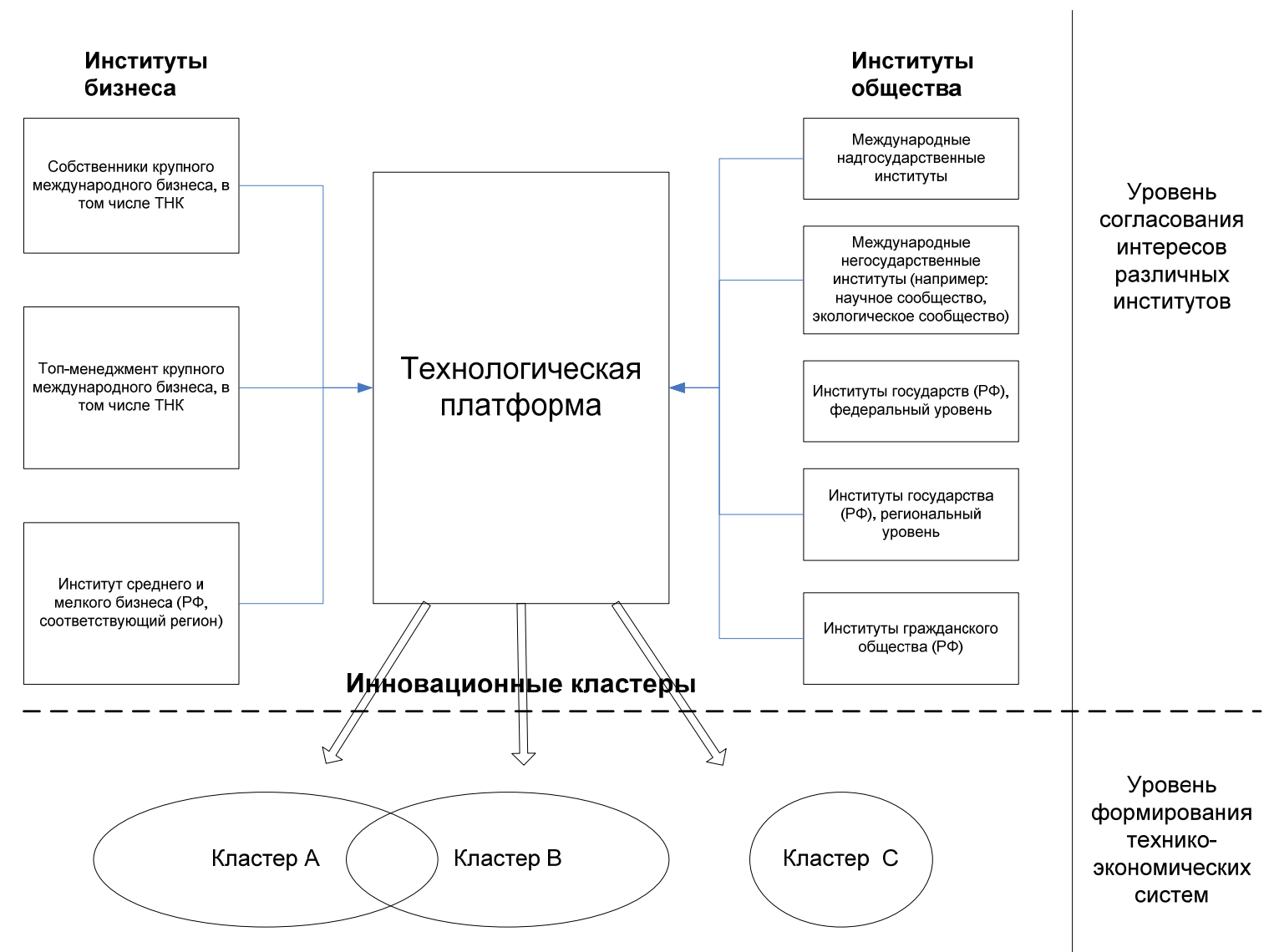

Рисунок 4. Концептуальная схема формирования инновационных кластеров на основе технологических платформ

Как правило, данная тенденция берет верх там, где в качестве локомотива продвижения кластерной политики выступает преимущественно государство, а бизнес и гражданское общество либо устранены, либо самоустранились от принятия решений о кластерном развитии территории. На рисунке 4 приведена концептуальная схема формирования инновационных кластеров на основе технологических платформ. В данной схеме достаточно четко видна основополагающая роль технологических платформ при формировании инновационных кластеров.

В заключение следует отметить, что задача модернизации социально-экономической системы региона в условиях глобализации и инновационного развития может быть решена только при условии эффективной кластеризации экономического пространства на основе вовлечения всех заинтересованных институтов общества на базе технологических платформ.

\section{Список литературы}

1. Батукова Л.Р. Технологические платформы как методологический подход к модернизации социально-экономических систем в условиях глобализации, Теория и практика инновационной экономики: Монография / под науч. ред. А.Н. Ларионова. М: МАКС Пресс, 2011. С. 30-43.

2. Громыко Ю.В. Что такое кластеры и как их создавать // Восток. 2007. № 1, т. 42. URL: http://www.situation.ru (дата обращения: 15.03.2011).

3. Красноярский край: официальный портал / Администрация Губернатора Красноярского края / Анализ кластеров. URL: http://www.krskstate.ru/econom/socialeconomic/program/content/p11\# (дата обращения: 29.05.2010). 
4. Ленчук Е.Б., Власкин Г.А . Кластерный подход в стратегии инновационного развития зарубежных стран [Электронный http://www.ecfor.ru/pdf.php?id=2010/5/04 (дата обращения: 29.05.2010).

5. Методические рекомендации по реализации кластерной политики в субъектах Российской Федерации // Методические рекомендации подготовлены Министерством экономического развития России (письмо от 26.12.2008 г. № 20615-AК/Д19) URL: http://www.ir-pep.ru/analytics/innov/detail/?item_id=218.

6. Титов Д., Модернизация снизу при поддержке сверху // Экономика и жизнь. 2011. № 36 (9402). С. $1,4$.

7. Титов Д. Приложение к статье «Модернизация снизу при поддержке сверху» // Экономика и жизнь. 2011. № 36 (9402). С 1, 4. URL: http://www.egonline.ru/upload/iblock/dca/Proekt\%20dorojnaya\%20karta.pdf (дата обращения: 29.05.2010). 